\title{
Formação e inserção dos coordenadores de curso no ensino médio e técnico: o contexto das Escolas Técnicas Estaduais de São Paulo
}

Course coordinators in vocational education: a research about training and insertion in State Technical Schools of São Paulo Formación e inserción de coordinadores de cursos en la educación técnica profesional de grado medio: el contexto de las Escuelas Técnicas del Estado de São Paulo

\author{
Cristiano Pereira da Silva (iDa
} Paulo Roberto Prado Constantino (id b

Resumo

A pesquisa pretendeu delinear a inserção e formação dos coordenadores de cursos de ensino médio e técnico nas Escolas Técnicas Estaduais de São Paulo, ao explorar aspectos relacionados à trajetória histórica, inserção e a formação inicial e continuada destes profissionais no âmbito de um sistema público de educação profissional, o Centro Estadual de Educação Tecnológica Paula Souza. Por meio de uma pesquisa documental e de campo do tipo survey, de abordagem qualitativa, realizada entre 128 coordenadores de cursos de 75 Etecs, insere-se na possibilidade de expansão de uma literatura ainda incipiente sobre a coordenação de cursos na educação profissional, apontando resultados sobre a formação e inserção destes sujeitos, desvelando lacunas

\footnotetext{
a Centro Estadual de Educação Tecnológica Paula Souza, São Paulo, SP, Brasil. Mestre em Gestão e Desenvolvimento da Educação Profissional, e-mail: filepersonal@yahoo.com.br ${ }^{b}$ Centro Estadual de Educação Tecnológica Paula Souza, São Paulo, SP, Brasil. Doutor em Educação, e-mail: pconst2@gmail.com
} 
existentes, oportunidades de formação pouco exploradas, a constituição do grupo de profissionais enfocado. Estes resultados, em relação à formação dos coordenadores de curso, destacaram a necessidade de alinhamento da formação inicial e continuada aos temas relacionados à gestão de legislação e da informação, bem como aspectos pedagógicos e gestionários das unidades escolares. Quanto à sua inserção, apontouse a imperativa dotação e distribuição de carga horária suficiente para um melhor desempenho de suas atividades, bem como a importância dos incentivos variados ao desenvolvimento da função de coordenação. Em perspectiva, este ator emergiu como imprescindível para os processos e os resultados das escolas técnicas estaduais, desde seu primeiro reconhecimento histórico em 1988 e, posteriormente, acompanhando os movimentos de forte expansão institucional no início do século XXI.

Palavras-chave: Coordenação de curso. Educação profissional. Gestão Escolar. Ensino Técnico. Formação e inserção de gestores.

\section{Abstract}

The research intends to outline the training of the coordinators of vocational education courses in the State Technical Schools of São Paulo, by exploring aspects related to the historical trajectory and initial and lifelong training, within the scope of a public education system. Through a documentary and field qualitative research of the survey type, carried out among 128 course coordinators of 75 Etecs, it is inserted in the possibility of expanding a still incipient literature on the coordination of courses in vocational education, pointing out results on the training and insertion of these subjects, unveiling existing gaps, little explored training opportunities, the constitution of the focused group. These results, in relation to the training of course coordinators, highlighted the need for alignment of initial and lifelong training to topics related to legislation and information management, pedagogical and managerial aspects of schools. As for its insertion, it was pointed out the imperative allocation and distribution of sufficient hours for a better performance of its activities, as well as the importance of the varied incentives for the development of the coordination activity. In perspective, this actor has emerged as essential for the processes and results of state technical schools, since his first historical recognition in 1988 and, subsequently, following the movements of strong institutional expansion in the beginning of the 21st century.

Keywords: Course coordination. School management. Vocational education and training [VET]. Training and hiring of managers.

\section{Resumen}

La investigación busca perfilar la inserción y formación de los coordinadores de cursos técnicos en las Escuelas Técnicas Estatales de São Paulo, Brasil, explorando aspectos relacionados con la trayectoria histórica, la inserción y la formación inicial y continuada de estos profesionales dentro en el ámbito de un sistema público de educación profesional, el Centro Estatal de 
Educación Tecnológica Paula Souza. A través de una investigación documental y de campo del tipo, con enfoque cualitativo, realizada entre 128 coordinadores de cursos de 75 Etecs distribuidos por el Estado, se inserta en la posibilidad de ampliar una literatura aún incipiente sobre la coordinación de cursos en educación profesional, señalando resultados sobre la formación e inserción de estos sujetos, revelando brechas existentes, oportunidades de formación poco exploradas, la constitución del grupo focalizado de profesionales. Estos resultados, en relación a la formación de los coordinadores de cursos, destacaron la necesidad de alinear la formación inicial y continua con los temas relacionados con la legislación y la gestión de la información, así como con los aspectos pedagógicos y de gestión de las unidades escolares. En cuanto a su inserción, se señaló la imperativa asignación y distribución de horas suficientes para un mejor desempeño de sus actividades, así como la importancia de los variados incentivos para el desarrollo de la función coordinadora. En perspectiva, este actor se ha perfilado como imprescindible para los procesos y resultados de las escuelas técnicas estatales, desde su primer reconocimiento histórico en 1988 y, posteriormente, siguiendo los movimientos de fuerte expansión institucional de principios del siglo XXI.

Palabras clave: Coordinación de cursos. Educación profesional. Gestión escolar. Educación técnica. Formación e inserción.

\section{Introdução}

A coordenação de cursos é de suma importância para a condução das atividades educacionais na educação profissional técnica de nível médio (CONSTANTINO; POLETINE, 2018), exigindo competências relacionadas a uma sólida formação pedagógica e gestionária, a previsão e organização de recursos materiais e humanos; e também na articulação dos professores e auxiliares de docente, em relação à condução dos componentes curriculares previstos nos diferentes planos de cursos (CONSTANTINO; POLETINE, 2018).

Nas Escolas Técnicas Estaduais de São Paulo [Etecs], as atividades de coordenação de cursos na educação básica e nas habilitações técnicas integradas, concomitantes ou subsequentes ao ensino médio, são exercidas por professores designados para a função em confiança da direção local (cf. CENTRO ESTADUAL DE EDUCAÇÃO TECNOLÓGICA PAULA SOUZA - CEETEPS, 2015), aos quais são atribuídas horas de atividades remuneradas [HAE] para o desenvolvimento de seus projetos de gestão por curso [ou um grupo de cursos], em cada uma das escolas.

Neste cenário, o objetivo geral da pesquisa foi delinear a inserção e a formação de um grupo de coordenadores de cursos de ensino médio e técnico nas Escolas 
Técnicas Estaduais de São Paulo, ao explorar aspectos relacionados à inserção, trajetória institucional e a formação inicial e continuada destes profissionais, no âmbito de um sistema público de educação profissional - o Centro Estadual de Educação Tecnológica Paula Souza [CEETEPS ou Centro Paula Souza].

Entre os objetivos específicos, contou-se com a possibilidade de expandir uma literatura ainda limitada sobre a coordenação de cursos na educação profissional, ao apontar resultados sobre a formação e inserção destes sujeitos, desvelando lacunas existentes ou oportunidades de formação pouco exploradas, e reconhecer a constituição grupal destes profissionais nas escolas técnicas, com dados sobre a perspectiva que possuem quanto às suas funções, sua inserção no quadro funcional e o clima organizacional escolar de sua unidade.

Com este direcionamento e para investigar estas questões de inserção e formação, foi realizada uma pesquisa de campo do tipo survey, de caráter descritivo e também exploratório, com o emprego de formulários on-line coletados entre os meses de outubro e dezembro de 2020, junto a um público de 128 coordenadores de cursos atuantes no ano de 2020, oriundos de uma amostragem de 75 Etecs de quatro diferentes regiões de supervisão educacional do Estado de São Paulo. A esta abordagem, reuniu-se uma pesquisa documental sobre fontes diversas, abertas e fechadas à consulta pública.

\section{Fundamentos da investigação}

De início, as bases da pesquisa foram constituídas sobre uma literatura relacionada à educação profissional, gestão educacional, formação profissional e a coordenação de cursos. Após reconhecer o marco legal sobre a educação profissional no Brasil (BRASIL, 1996; 2021b), no aspecto da formação foram perscrutados temas como a formação inicial e a insuficiência desta no Brasil, formação continuada em serviço, responsabilidade institucional pela formação continuada; função, destinação e os eixos fundantes das formações (REHEM, 2009; LÜCK, 2000; GOMES; MARINS, 2003; BRASIL，2021b; AQUINO; MUSSI, 2001; BRASIL， 1996; ESTEVES; RODRIGUES, 1993; GATTI, 2008).

A seguir, passou-se ao exame da literatura sobre possíveis eixos articuladores (LIBÂNEO, 2013; LÜCK, 2009) da gestão educacional, especialmente aplicados ao 
contexto da educação básica, mas que ecoam também em outros níveis e modalidades, como a educação profissional, tal como adotados (cf. CONSTANTINO; POLETINE, 2018) ou adaptados nesta pesquisa. Esboçou-se um quadro conceitual relacionado à gestão educacional, aos fundamentos legais da gestão participativa e democrática da educação e às aproximações desta gestão educacional à coordenação de cursos na educação profissional (CONSTANTINO; POLETINE, 2018; LIBÂNEO, 2013; ASSEMBLEIA LEGISLATIVA DO ESTADO DE SÃO PAULO - ALESP, 2016; BRASIL, 1996; 2014; 2021b; LÜCK, 2000; 2009; NÓVOA, 2009).

Tome-se, por exemplo, o campo em que Libâneo (2013) reconhecia grandes eixos de atuação da gestão escolar ${ }^{1}$. Lück (2009) considerava-os dimensões da gestão escolar, com suas necessárias competências (LÜCK, 2009). São exemplos de duas das análises e classificações possíveis, no entanto, a fim de simplificar o reconhecimento destes eixos de atuação dentre os coordenadores na pesquisa, seguiu-se com o instrumental de Libâneo (2013).

Quanto à coordenação de cursos, entende-se aqui como uma função específica de gestão educacional, pois no contexto da educação profissional, tal como ocorre no ensino superior, se espera "que ele mobilize e execute ações transformadoras na gestão dos serviços e dos recursos pedagógicos, tendo como objetivo principal a melhoria da qualidade do processo de ensino e de aprendizagem" (MARQUESIN; PENTEADO; BAPTISTA, 2008, p. 10).

$\mathrm{Na}$ literatura nacional sobre a coordenação de cursos superiores (p. ex.: SEABRA; PAIVA; LUZ, 2015; MARQUESIN; PENTEADO; BAPTISTA, 2008; BARROS; ARAGÃO, 2006), as atividades e ações estavam relacionadas ora ao desenvolvimento gerencial ou burocrático, com ênfase na perspectiva empresarial ou corporativa, ora na perspectiva educacional e de gestão participativa, debatendo as atribuições do coordenador sob este olhar.

Entre os trabalhos que tratavam especificamente da coordenação de cursos na educação profissional técnica de nível médio, os destaques ficaram sobre uma publicação

\footnotetext{
${ }^{1}$ Dirigindo-se aos gestores de modo mais amplo, Libâneo (2013) reconhecia quatro grandes eixos para a organização da escola: a vida escolar, os processos de ensino e de aprendizagem, o apoio técnico-administrativo e a relação escola-comunidade. Nota-se que a atividade de coordenação de cursos nas Etecs mesclaria estes eixos (CONSTANTINO, 2017).
} 
pioneira do CEETEPS, oriunda de um curso ministrado aos coordenadores no início dos anos 2000 (ARAÚJO; COVELLO, 2000), uma dissertação sobre a coordenação de cursos técnicos em Enfermagem (GUTSCHOW, 2007) e, finalmente, o trabalho de Constantino e Poletine (2018), mais conectado a esta pesquisa.

$\mathrm{Na}$ instituição focalizada, o primeiro registro histórico que se identificou da presença dos coordenadores nas Etecs é de 1988, com a Deliberação no 09/1988 (CEETPS, 1988), que apresentava a regulação da função dos coordenadores de área, em um diapasão próximo do conceito de gestão — e de gestor — cristalizado por Libâneo (2013) e Marquesin, Penteado e Baptista (2008). No excerto da Deliberação, eram os apresentados como responsáveis por:

elaborar, supervisionar e executar o planejamento de ensino, orientar, coordenar e avaliar as atividades docentes em relação às diretrizes traçadas pelas Unidades e à otimização dos recursos físicos e didáticos disponíveis [...]. (CEETPS, 1988, p. 34)

O coordenador de área seria o principal ator na articulação pedagógica de professores e auxiliares, em relação ao restante da estrutura funcional das escolas nos anos finais de 1980. No início do século XXI, a instituição passaria por um momento de forte expansão, ampliando o número de Etecs e de matrículas, em um processo examinado por Lima (2020) em pesquisa recente. A coordenação de área teria sido, na esteira deste processo, a função que aglutinaria os professores do mesmo curso ou eixo tecnológico, desde os anos de 1988 e, mais decisivamente, a partir desta movimentação de expansão institucional do final de século XX, o que defendiam Constantino e Poletine (2018), especialmente ao considerarem que a função de coordenação pedagógica nas Etecs seria implantada somente nas duas décadas seguintes (cf. SILVA; CONSTANTINO, 2019).

Quanto à formação dos antigos coordenadores de área, em 1999 o Centro Paula Souza ofereceria a primeira iniciativa que identificamos para a formação continuada em serviço em escala institucional: um curso destinado a 90 coordenadores de área do Estado, denominado "Construção da Identidade do Coordenador de Área”, documentado em uma publicação (ARAÚJO; COVELLO, 2000) de cinco volumes. O quinto destes seria dedicado exclusivamente aos textos sobre a coordenação de área, nos quais encontram-se os artigos de Boschiero (2000) 
e Cecconi (2000), com referências para a compreensão destes primeiros momentos da atividade no Centro Paula Souza.

Iniciativas de alcance institucional seriam identificadas novamente a partir do ano de 2011, com os três encontros de formação promovidos pela supervisão educacional da Região Marília e Presidente Prudente, dos quais tomaram parte 182 coordenadores de área das escolas situadas naquela região. A iniciativa se alastraria às demais regiões do Estado, nos anos seguintes, por meio dos encaminhamentos dados pelo Grupo de Supervisão Educacional - Gestão Pedagógica, que coordenava o trabalho de supervisão entre as diversas regionais.

Dispostas estas informações e considerações de cunho histórico, cotejadas aos eixos de atuação da gestão reconhecidos por Libâneo (2013), Lück (2009) e Constantino e Poletine (2018), obtivemos o ponto de partida para uma reflexão e análise das atribuições atuais e legalmente dispostas aos coordenadores de cursos inseridos nas Etecs, bem como os aspectos manifestados na pesquisa de campo quanto à sua formação inicial e continuada, o que seria o movimento seguinte da investigação.

\section{Metodologia e caracterização}

O cenário desta pesquisa qualitativa está delimitado em um grupo de Escolas Técnicas Estaduais, sobre o qual existe uma previsão de atuação dos coordenadores identificada no Regimento Comum das Etecs de 2013 (CEETEPS, 2013) em vigência; e a regulação específica da função existente [coordenação de curso] desde o ano de 2012 (CEETEPS, 2012), atualizada posteriormente em 2015 (CEETEPS, 2015).

Em 2020, 223 Etecs eram administradas pelo Centro Estadual de Educação Tecnológica Paula Souza, uma autarquia de Governo vinculada à Secretaria de Desenvolvimento Econômico. Distribuídas por todas as regiões, estas escolas atendiam mais de 224 mil estudantes gratuitamente, somente nos ensinos médio e técnico (CETEC, 2020b), além de oferecer formação inicial e qualificação básica, ensino superior em suas 73 Faculdades de Tecnologia [Fatecs] e contar com uma Unidade de Pós-Graduação, Extensão e Pesquisa (CEETEPS, 2020a).

Aliada à pesquisa documental, na pesquisa de campo optou-se por consultar uma amostragem de 75 escolas em quatro regiões de supervisão educacional distintas, 
o que representaria um terço do total de Etecs do Estado de São Paulo, com unidades que apresentariam diversidade de público, localidade e amplitude no atendimento, tendo sido definidas por abarcarem estes critérios de variedade, em diferentes regionais na capital e no interior do Estado, a saber, na Regional de Campinas Norte, Grande São Paulo Leste, São José do Rio Preto/Central/Barretos e Sorocaba ${ }^{2}$. Um contato inicial foi estabelecido com os supervisores responsáveis pelos Núcleos de Administração Regional. Com o aceite das quatro regiões, deu-se sequência à tramitação da documentação junto aos departamentos competentes do CEETEPS 3 .

Quanto aos objetivos, tratou-se de uma pesquisa descritiva (GIL, 2008), pois procurava "a descrição das características de determinada população ou fenômeno" (GIL, 2008, p. 28). No entanto, posicionou-se na fronteira com os objetivos de caráter exploratório, ao ultrapassar a simples identificação ou caracterização, pretendendo aprofundar-se ou oferecer uma nova visão do problema (GIL, 2008).

O perfil da investigação foi derivado de estudos realizados na esfera do Grupo de Pesquisa 'Gestão, Avaliação e Organização da Educação Profissional', alinhado ao projeto “Atores da Educação Profissional e Tecnológica” da Unidade de Pós-Graduação, Extensão e Pesquisa do CEETEPS, que aborda aspectos educacionais e gestionários dos sujeitos e equipes presentes em escolas técnicas e faculdades de tecnologia públicas ligadas ao Centro Paula Souza e outras instituições de Educação Profissional e Tecnológica — tais como diretores de escolas, coordenadores pedagógicos, coordenadores de curso, orientadores educacionais, auxiliares de docente, entre outros.

\footnotetext{
2 Em 2020 as Etecs e Fatecs estavam subdivididas entre 12 Núcleos de Administração Regional [NRA], cobrindo todo o território paulista, a saber: Bauru e Araçatuba [13 Etecs e 4 Fatecs], Campinas Norte [16 - 3], Campinas Sul [16 - 8], Grande São Paulo Leste [25 - 6], Grande São Paulo Noroeste [30 - 7], Grande São Paulo Sul e Baixada Santista [25 - 10], Itapeva e Registro [9 - 0], Marília e Presidente Prudente [22 - 7], Ribeirão Preto [19 - 5], São José do Rio Preto [16 - 8], Sorocaba [18 - 7], Vale do Paraíba e Litoral [14 - 8].

${ }^{3}$ Os formulários contaram com a adesão livre e esclarecida dos coordenadores consultados por e-mail, conforme aprovação da Comissão de Ética em Pesquisa da Unidade de PósGraduação, Extensão e Pesquisa do CEETEPS [Parecer EP n 13/2020] e autorizações internas da Unidade do Ensino Médio e Técnico - Cetec e seus departamentos [Despacho GSE/GEPED $n^{\circ} 387 / 2020$, Termo de Anuência Institucional]. Um teste do formulário foi encaminhado a dois coordenadores previamente, para possíveis ajustes antes da consulta efetiva. 130 coordenadores responderam ao chamado definitivo e 128 deles concordaram em participar, entre os meses de novembro e dezembro de 2020, o que representou uma amostragem de cerca de $25 \%$ dos coordenadores de curso existentes naqueles quatro NRA, com adesão proporcional entre as regiões.
} 
Quanto ao delineamento metodológico, envolveu uma pesquisa documental e também do tipo survey (GIL, 2008) baseada em formulários online (SOUZA, 2020) com 17 itens fechados e 6 abertos, sendo o último deles de dissertação espontânea. Segundo Gil (2008), estas pesquisas de campo se caracterizam pela interrogação direta do público-alvo em que, “[...] basicamente, procede-se à solicitação de informações a um grupo significativo de pessoas acerca do problema estudado para em seguida, mediante análise quantitativa, obter as conclusões correspondentes dos dados coletados" (GIL, 2008, p. 55). O teor das questões seria forjado a partir de estudos anteriores (CONSTANTINO; POLETINE, 2018; CONSTANTINO; AZEVEDO; MENINO, 2021; BOSCHIERO, 2000) e pesquisas longitudinais de fôlego (ORGANISATION FOR ECONOMIC CO-OPERATION AND DEVELOPMENT - OECD, 2019). Extraídos os dados, foram tabulados com o auxílio de planilhas Microsoft Excel e do Google Forms. A última questão aberta do formulário não será abordada neste artigo, em razão de seu escopo e extensão.

Após um tratamento simples, pretendeu-se a projeção desta amostragem de coordenadores sobre a totalidade do universo disponível no Centro Paula Souza, a saber, os 2.047 coordenadores de curso que atuavam nas Etecs por todo o Estado de São Paulo em 2020. Também foram empregadas abordagens qualitativas fundadas na análise textual.

\section{Resultados}

Um primeiro momento desta consulta foi o da caracterização do grupo de coordenadores de curso. Quanto a identificação por gênero, verificaram-se $53 \%$ homens e $46 \%$ de mulheres, sendo que 1\% não se manifestou. Quanto ao corte por faixa etária, somente 7\% dos coordenadores estavam situados entre 26-30 anos e predominou a faixa acima de 40 anos, que eram 52,4\% dos pesquisados. A experiência profissional nas escolas técnicas estaduais também foi um dado relevante nesta caracterização: 47\% apresentaram de 6 a 10 anos de experiência. Somente 11\% eram profissionais que atuavam entre 1-5 anos nas Etecs e 8,5\% tinham mais de 20 anos de docência nestas escolas. Partindo desta caracterização inicial, apresentam-se os resultados obtidos nos formulários quanto à inserção e formação profissional dos 
coordenadores de curso, subdividindo-os em seções temáticas e dialogando, sempre que possível, com os documentos oficiais e a literatura consultada.

\section{Formas de inserção e as atribuições funcionais prescritas aos coordenadores de cursos das Etecs}

As coordenações de cursos das Etecs são responsáveis por um conjunto de ações destinadas ao planejamento do ensino, à supervisão de sua execução, ao controle das atividades docentes em relação às diretrizes didático-pedagógicas e administrativas, bem como a otimização dos recursos físicos e didáticos disponíveis para os cursos mantidos pelo Centro Paula Souza (CONSTANTINO; POLETINE, 2018).

Para sua indicação como Coordenador de Curso, segundo o Artigo $3^{\circ}$ da Deliberação CEETEPS 19, de 16-07-2015 (CEETEPS, 2015), o docente-candidato deverá preencher, cumulativamente, os seguintes requisitos: ser contratado por prazo indeterminado, estar em exercício no CEETEPS por no mínimo um ano, sendo portador de licenciatura plena ou equivalente, e ministrar aulas para, ao menos, uma turma do curso que será coordenado. Em casos excepcionais, sua indicação deverá ser submetida à supervisão educacional regional (CEETEPS, 2015; 2018).

Também está prevista a realização de um processo eleitoral entre pares. Elaborada uma lista com a relação de interessados na função, todos os docentes envolvidos naquele curso podem votar. Por votação simples e secreta, a diretoria de serviços administrativos da Etec coleta a lista e o vencedor deverá apresentar um projeto de gestão, que será submetido à análise da Direção de Escola e da Coordenação Pedagógica.

Após este processo, o diretor de Etec irá designar o coordenador de curso apresentando documentos que comprovem os requisitos exigidos, para que a área de projetos do Centro Paula Souza calcule horas-atividade específicas [HAE] para o desenvolvimento das atividades e, somente depois de aprovado pelo Coordenador do Ensino Médio e Técnico, o eleito poderá exercer suas funções.

O critério de cálculo para resultar o número total de horas-atividade específicas [HAE] semanais destinadas à unidade escolar está previsto na Instrução CETEC n ${ }^{\circ}$ 002, de 28 de junho de 2018 (CEETEPS, 2018), especificando também o mínimo de 6 
horas para que o Coordenador de Curso realize as suas atividades. Conforme previsto no Artigo $4^{\circ}$ da Deliberação (CEETEPS, 2015), o diretor poderá definir que um mesmo coordenador realize a coordenação de mais de um curso, desde que pertençam ao mesmo eixo tecnológico e/ou o professor esteja habilitado para tal, podendo também definir, para os casos do ensino médio e do técnico integrado, um coordenador para cada área de conhecimento, ou um para a Base Nacional Comum Curricular e outro para a Parte Profissional. As designações anuais devem ocorrer a partir do primeiro dia útil de fevereiro e o término em 31 de janeiro do ano subsequente, podendo atuar de forma ininterrupta, situação que passou a valer a partir da Deliberação CEETEPS n ${ }^{\circ}$ 06, de 2012 (CEETEPS, 2012), pois, até esta publicação, os coordenadores somente poderiam permanecer na função por quatro anos.

O Regimento Comum das Etecs, contido na Deliberação CEETEPS nº 003, de 18 de julho de 2013 (CEETEPS, 2013), além de apresentar a figura do coordenador em seu Artigo 26, I - "as Coordenações de Curso" e II os "Conselhos de Classe", descreve seu vínculo ao Conselho de Classe, no Artigo 27, reforçando a dimensão coletiva (NÓVOA, 2009) de seu trabalho. Esta dimensão coletiva de atuação implicaria em atenção à colaboração e ao trabalho em equipe, para uma "intervenção conjunta nos projetos educativos de escola. O exercício profissional organiza-se, cada vez mais, em torno de 'comunidades de prática', no interior de cada escola [...]" (NÓVOA, 2009, p. 31), o que se esperaria também na gestão dos coordenadores.

No levantamento documental desta investigação, foi possível identificar e categorizar os principais eixos de atuação presentes no regulamento da atividade, a Deliberação CEETEPS no 19/2015, que “dispõe sobre a Coordenação de Curso nas Escolas Técnicas Estaduais do CEETEPS” (CEETEPS, 2015, p. 41). Partindo desta diversidade e complexidade contida nas atribuições funcionais é que se constituiu a preliminarmente a pesquisa e a posterior abordagem dos dados coletados em campo, buscando a interlocução com a literatura e o trabalho prescrito: 
Quadro 1 - Atribuições da coordenação de curso descritas na Deliberação CEETEPS n¹9/2015, organizadas por eixos temáticos de atuação

\begin{tabular}{|c|c|}
\hline $\begin{array}{l}\text { Eixos de atuação da } \\
\text { coordenação de curso }\end{array}$ & $\begin{array}{l}\text { Atribuições da Coordenação de Curso } \\
\text { Deliberação CEETEPS - Nº 19/2015 }\end{array}$ \\
\hline $\begin{array}{l}\text { COORDENAÇÃO DO PROJETO } \\
\text { PEDAGÓGICO NOS CURSOS }\end{array}$ & $\begin{array}{l}\text { II - coordenar o desenvolvimento do trabalho docente, } \\
\text { assegurando o alinhamento entre os Planos de Trabalho } \\
\text { Docente com o Plano de Curso e Diário de/da Classe, sendo o } \\
\text { último em periodicidade semanal; } \\
\text { XV - elaborar a programação das atividades de sua área de } \\
\text { atuação, assegurando a articulação com as demais áreas da } \\
\text { gestão escolar; }\end{array}$ \\
\hline $\begin{array}{l}\text { CUMPRIMENTO DA CARGA } \\
\text { HORÁRIA E DO CALENDÁRIO } \\
\text { ESCOLAR }\end{array}$ & $\begin{array}{l}\mathrm{XI} \text { - acompanhar o cumprimento das aulas previstas e dadas e } \\
\text { das reposições/substituições quando houver, no curso que } \\
\text { coordena, informando a Direção regularmente; }\end{array}$ \\
\hline $\begin{array}{l}\text { ATIVIDADES EXTRAS E } \\
\text { VISITAS TÉCNICAS }\end{array}$ & $\begin{array}{l}\text { VII - participar das atividades destinadas a propor e/ou } \\
\text { promover cursos extracurriculares de curta duração, palestras e } \\
\text { visitas técnicas; }\end{array}$ \\
\hline $\begin{array}{l}\text { GESTÃO DA ATUAÇÃO DO } \\
\text { AUXILIAR DE DOCENTE }\end{array}$ & $\begin{array}{l}\mathrm{V} \text { - orientar, acompanhar e gerenciar a atuação dos Auxiliares de } \\
\text { Docentes, de forma a organizar, preparar e auxiliar o } \\
\text { desenvolvimento das aulas práticas nos ambientes didáticos; }\end{array}$ \\
\hline $\begin{array}{l}\text { AVALIAÇÃO DO } \\
\text { DESEMPENHO DOCENTE }\end{array}$ & $\begin{array}{l}\text { VIII - avaliar o desempenho dos Docentes e Auxiliares de } \\
\text { Docentes sob sua coordenação; }\end{array}$ \\
\hline $\begin{array}{l}\text { CONSELHO ESCOLAR E } \\
\text { INSTÂNCIAS PARTICIPATIVAS }\end{array}$ & XIII - integrar o Conselho de Escola; \\
\hline ATIVIDADES DE ESTÁGIO & $\begin{array}{l}\text { IV - coordenar as atividades vinculadas ao estágio } \\
\text { supervisionado, garantindo o pleno desenvolvimento da } \\
\text { formação profissional; }\end{array}$ \\
\hline $\begin{array}{l}\text { TRABALHO DE CONCLUSÃO } \\
\text { DE CURSO }\end{array}$ & $\begin{array}{l}\text { XII - supervisionar e coordenar o planejamento e a execução dos } \\
\text { trabalhos de conclusão de curso (TCC), juntamente com os } \\
\text { professores encarregados da orientação dos alunos; }\end{array}$ \\
\hline $\begin{array}{l}\text { AVALIAÇÃO E RECUPERAÇÃO } \\
\text { DE APRENDIZAGEM }\end{array}$ & $\begin{array}{l}\text { III - orientar e acompanhar a programação das atividades de } \\
\text { recuperação e de progressão parcial, a partir das diretrizes } \\
\text { estabelecidas pelo Coordenador de Projetos Responsável pela } \\
\text { Orientação e Apoio Educacional; } \\
\text { VI - manifestar-se, quando convocado, sobre pedidos de } \\
\text { aproveitamento de estudos, bem como sobre pedidos de } \\
\text { reconsideração e recursos referentes aos resultados finais de } \\
\text { avaliação discente, de acordo com as Deliberações expedidas } \\
\text { pelo Conselho Estadual de Educação; }\end{array}$ \\
\hline $\begin{array}{l}\text { PROSPECÇÃO DE CENÁRIOS } \\
\text { NA UNIDADE E NO CAMPO } \\
\text { DE ATUAÇÃO }\end{array}$ & $\begin{array}{l}\text { XIV - propor a pesquisa, estudos e análise das tendências de } \\
\text { mercado e inovações no campo das ciências e tecnologias, } \\
\text { promovendo reformulações curriculares que incorporem } \\
\text { avanços e atendam as demandas do mundo do trabalho; } \\
\text { XVI - promover reuniões de curso, de acordo como Calendário } \\
\text { Escolar homologado, para alinhar e refletir sobre indicadores de } \\
\text { desempenho, processo de ensino-aprendizagem, organização } \\
\text { das aulas práticas e demais estratégias de ensino do (s) curso (s). }\end{array}$ \\
\hline $\begin{array}{l}\text { PLANEJAMENTO } \\
\text { ESTRATÉGICO DA ETEC }\end{array}$ & $\begin{array}{l}\text { I - participar da elaboração e execução do Projeto Político } \\
\text { Pedagógico (PPP) e do Plano Plurianual de Gestão (PPG); }\end{array}$ \\
\hline $\begin{array}{l}\text { INTERAÇÕES COM A EQUIPE } \\
\text { PEDAGÓGICA SOBRE O } \\
\text { CORPO DISCENTE }\end{array}$ & $\begin{array}{l}\text { IX - assessorar a Direção em suas decisões sobre matrícula e } \\
\text { transferência, agrupamento de alunos, organização de horários } \\
\text { de aulas e calendário escolar, em conjunto com o Coordenador } \\
\text { de Projetos Responsável pela Orientação e Apoio Educacional; }\end{array}$ \\
\hline $\begin{array}{l}\text { PARTICIPAÇÃO EM BANCAS E } \\
\text { PROCESSOS }\end{array}$ & $\begin{array}{l}\text { X - integrar bancas de processo seletivo e concurso público e } \\
\text { certificação de competências, realizando a avaliação técnica dos } \\
\text { candidatos; }\end{array}$ \\
\hline
\end{tabular}

Fonte: Adaptado de CEETEPS, 2015, p. 41-42; CONSTANTINO, 2017; CONSTANTINO; POLETINE, 2018. 
Das 16 atribuições apresentadas na Deliberação (CEETEPS, 2015), considerou-se que 11 [69\%] estavam diretamente relacionadas com aspectos pedagógicos [II, III, IV, V, VI, VII, VIII, IX, XI, XII, XV], o que reveste a coordenação de curso de um papel fortemente associado às questões do ensino e da aprendizagem, listada por Libâneo (2013) como uma das bases da gestão educacional efetiva. As outras três dimensões mencionadas pelo autor também seriam contempladas, como a atenção à vida escolar [I, XVI], ao apoio técnico-administrativo $[\mathrm{X}]$ e às relações escola-comunidade [XIII, XIV $]^{4}$.

As respostas fornecidas pelos 128 coordenadores foram agrupadas para reconhecer, a partir das demandas apontadas pela documentação oficial, aspectos da inserção destes profissionais, possíveis lacunas existentes ou oportunidades de formação, além das perspectivas que possuem quanto ao desempenho de suas funções, seu rendimento e as relações com o clima organizacional escolar.

\section{A inserção dos profissionais na coordenação de cursos}

$\mathrm{Na}$ inserção por gênero, como apontado anteriormente na caracterização geral da pesquisa, verificaram-se 53\% homens e 46\% de mulheres e 1\% não se manifestou. É uma relação distinta da encontrada na gestão escolar do país, de acordo com pesquisas longitudinais que apontam as mulheres como maioria [76\%] nos postos principais [direção] de gestão de unidades escolares da educação básica (OECD, 2019). Tal fato poderia ser explicado pela atuação de origem destes coordenadores de cursos, pois $82 \%$ dos consultados são professores de componentes curriculares da parte profissional do ensino técnico - onde predominam os homens no CEETEPS —, e não do ensino médio [BNCC].

Quanto à inserção na atividade por faixa etária, somente 7\% dos coordenadores estavam situados entre 26-30 anos. Trata-se aqui de identificar uma atividade em que são pouco prestigiados os professores jovens, afinal, 21,1\% tinham 50 anos ou mais; e 31,3\% entre 41-50. Predominou a faixa acima de 40 anos, que eram 52,4\% dos pesquisados.

\footnotetext{
${ }^{4}$ Não se trata de uma classificação estática, mas dinâmica: relações escola-comunidade e a vida escolar (LIBÂNEO, 2013) podem ser faces de uma mesma atribuição funcional, como "integrar o Conselho de Escola" (CEETEPS, 2015, p. 42).
} 
Quanto à experiência geral docente e tempo de atuação nas Etecs, lembramos que coordenadores de cursos nas Etecs são professores que foram designados temporariamente à função, ainda que possam ser reconduzidos indefinidamente. Com esta consideração, notou-se que a experiência profissional nas escolas técnicas estaduais também seria um dado relevante nesta caracterização: 47\% apresentaram de 6 a 10 anos de experiência. Somente 11\% eram profissionais que atuavam entre 1-5 anos nas Etecs e 8,5\% tinham mais de 20 anos de docência nestas escolas. Esta faixa intermediária de experiência escolar numa Etec - de 6 a 10 anos - seria predominante, mas não um elemento relevante para a inserção na coordenação de cursos, como se observará a seguir.

Ao analisar o tempo específico de atuação na coordenação de cursos das Etecs, notou-se uma rotatividade considerável nos postos de trabalho: 59,4\% estavam na função entre 1 e 5 anos e 8,6\% ainda não haviam completado um ano na data de resposta ao formulário. Somente 3\% tinham 11 anos ou mais anos em atividade, juntando-se ao contingente de 29\% que atuava de 6 a 10 anos na coordenação. Esta experiência seria um requisito para a legitimação do trabalho da coordenação de cursos, pois sua atuação funcional (CEETEPS, 2015) prevê aspectos de supervisão interpares, prospecções na área profissional, contribuições relacionadas à avaliação do trabalho docente e institucional (CONSTANTINO; POLETINE, 2018), o que exigiria considerável experiência destes sujeitos para cobrir tal amplitude de atividades. Futuramente seria útil debater com esta terça parte identificada dos coordenadores de curso mais estáveis [acima de 6 anos de experiência], para a formulação de propostas e políticas para a coordenação de cursos da educação profissional e o incremento da função, o que se reconhece como oportunidade para estudos aprofundados neste público específico, em momentos posteriores.

Sobre o tipo de habilitação [ou cursos] que coordenavam no momento, revelou-se que 30\% estavam em habilitações técnicas integradas ao ensino médio e apenas $2 \%$ coordenavam turmas de ensino médio propedêutico, o que reflete os esforços da instituição para integrar a totalidade de suas habilitações de ensino médio ao ensino técnico nos últimos anos. No entanto, esta ampla participação do ensino 
integrado ainda não suplantaria os cursos técnicos concomitantes ou subsequentes ${ }^{5}$, pois $67,3 \%$ dos coordenadores atuavam preferencialmente neles.

Outro dos questionamentos procurava evidenciar as motivações pelas quais estes professores de ensino médio e técnico haviam optado por atuar na coordenação de cursos, uma vez que assumiriam muitas responsabilidades adicionais em relação às aulas que possuiriam costumeiramente:

Gráfico 1 - Motivações para se tornar um[a] coordenador[a] de curso [em percentuais]

A coordenação me permitia oferecer uma contribuição à sociedade e a comunidade escolar

A coordenação me permitia ajudar mais os professores e alunos dentro da escola

Os horários de trabalho eram mais adequados aos compromissos da minha vida pessoal

Era uma maneira de completar minha carga horária de trabalho

Era uma maneira de permanecer na cidade onde resido

Era uma opção de carreira mais estável

- Grande importância

- Moderada importância

- Pouca importância

- Não foi importante

Fonte: (AUTORES, 2021).

Questões funcionais como completar a carga horária ou ter uma carreira mais estável foram pouco destacadas pelos respondentes. No entanto, um senso de comprometimento com a causa educacional foi apontado como a razão principal para acessarem a coordenação de cursos: 77\% atribuíram grande importância ao fato de que a função lhes permitiria uma contribuição decisiva à escola e a comunidade e $71 \%$ entenderam que na coordenação de curso estariam em condições de ajudar mais o trabalho pedagógico dos colegas professores e dos alunos dentro da Etec.

\footnotetext{
${ }^{5}$ Cursos técnicos concomitantes e/ou subsequentes são ofertados no Centro Paula Souza em diferentes turnos, com presença mais intensa no período noturno: entre todas as 6.262 turmas de ensino médio e técnico ofertadas em todo o Estado de São Paulo, em suas diversas modalidades e períodos, 3.068 [49\%] eram de ensino técnico modular no período noturno (CETEC, 2020).
} 


\section{A formação dos coordenadores de cursos}

Para Libâneo (2013), a construção e o fortalecimento da identidade profissional na educação precisariam tomar parte no "currículo e nas práticas de formação inicial e continuada" (LIBÂNEO, 2013, p. 71). Nos tópicos a seguir, pretende-se a exposição dos resultados relacionados à formação inicial dos coordenadores em nível de graduação e suas complementações pedagógicas, a formação continuada em nível de pós-graduação e a formação continuada de curta duração ou em serviço.

Ao verificar a formação inicial em nível de graduação, 67\% dos coordenadores não possuíam uma licenciatura [eram principalmente bacharéis e alguns poucos, tecnólogos]. A formação para a docência, quando não foi obtida nas licenciaturas ou no curso de pedagogia, foi equacionada por meio dos programas de formação pedagógica complementar, ao constatar-se que 67\% dos entrevistados [entre os não licenciados inicialmente] dirigiu-se a um destes programas.

Outro dado relevante sobre a formação inicial é que 65,6\% dos coordenadores mencionaram não ter obtido nenhuma preparação específica para a coordenação de cursos nesta etapa de sua preparação profissional, e 25\% observaram a temática como um conteúdo esparso dentro de disciplinas de sua graduação. Esta é a primeira lacuna a se destacar: a da formação inicial, que poderia ser modificada nas licenciaturas e pedagogias; mas que certamente recairá como um compromisso inalienável sobre a formação continuada em serviço, que assumiria importância no âmbito institucional do CEETEPS, em cursos de curta duração identificados sistematicamente desde o ano de 2011 sobre o tema e destinados ao público-alvo em evidência.

Quanto à formação em nível de pós-graduação, o percentual de coordenadores de cursos qualificados foi significativo: somente $6 \%$ não possuíam este tipo de formação. A pós-graduação lato sensu predominou, com 87,5\% de especialistas dentre os 128 coordenadores consultados. Entre os que possuíam a formação strictu sensu, dentre os 128 coordenadores, apurou-se 21\% como mestres e 3\% de doutores. Estes indicadores posicionam estes sujeitos muito acima da média observada na educação básica nacional, pois o Censo Escolar da Educação Básica 2020 apresentou um percentual de 43,4\% de professores com algum tipo de pós-graduação no país (BRASIL, 2021a). 
Com respeito à formação continuada em serviço, procurou-se investigar qual seria o nível de informação dos coordenadores sobre as possibilidades deste tipo de formação: 91\% recebiam informações, internas ou externas ao CEETEPS, sobre cursos de formação continuada destinados pontualmente aos coordenadores de curso [73\% sempre, 18\% raramente]. 8,6\% alegaram nunca receber informação sobre o assunto. Importa, portanto, ressaltar que há uma circulação destas informações. O passo seguinte foi verificar, no período dos últimos doze meses, se os pesquisados participaram de alguma atividade de desenvolvimento ou formação profissional, em uma perspectiva educacional geral, não especificamente destinada à coordenação de cursos, dentro ou fora do Centro Paula Souza:

Gráfico 2 - Atividades de formação [com temática educacional ampla] desenvolvidas pelos coordenadores de curso nos últimos 12 meses, em percentuais

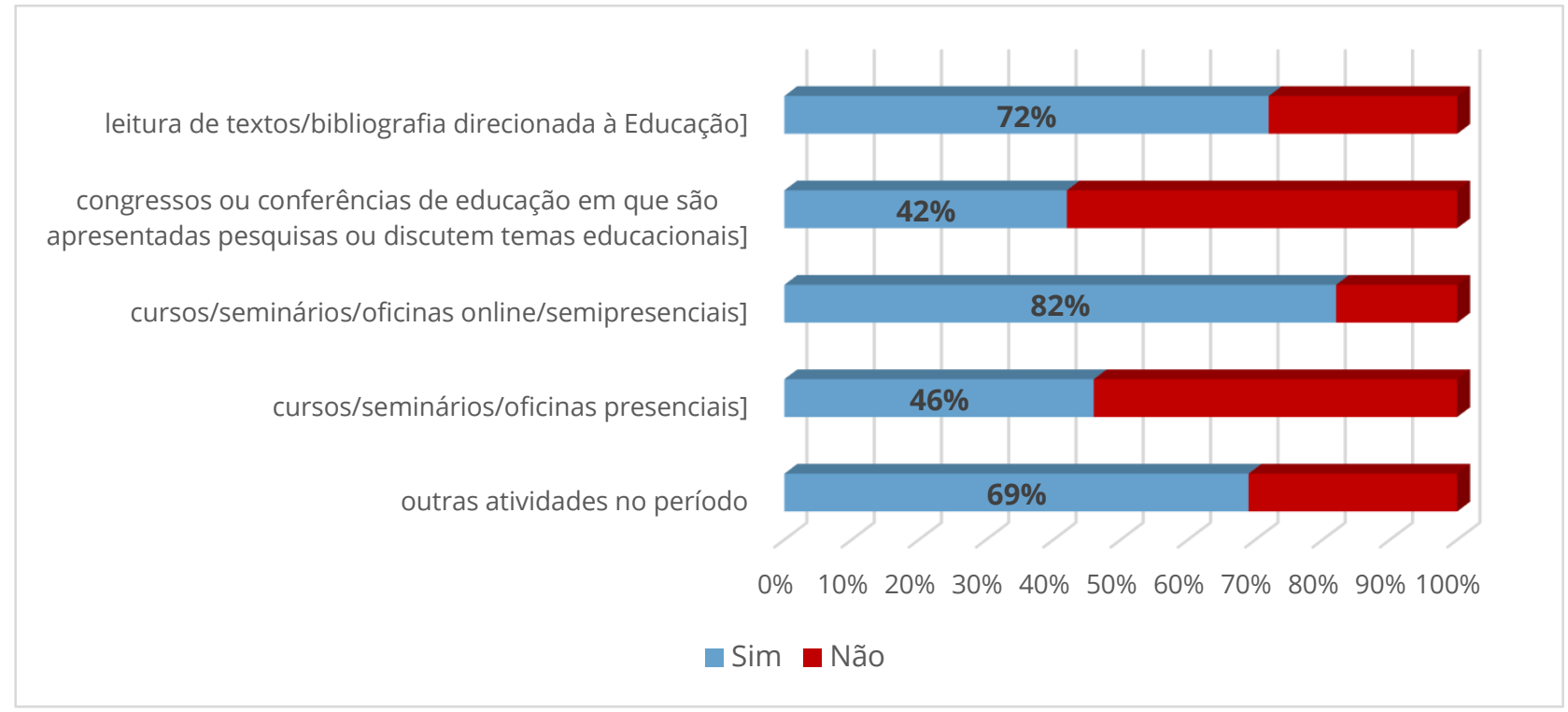

Fonte: (AUTORES, 2021).

A participação acentuada em cursos de formação online pode ser inferida pelas condições de isolamento social ocasionadas pela pandemia de COVID-19 [que teriam impactado ao menos sete meses dos últimos doze referidos na sentença expressa] e consequente proliferação das oportunidades de cursos no formato a distância.

Ao aprofundarmos o questionamento, avançou-se sobre os doze últimos meses em que teriam participado de alguma atividade de desenvolvimento ou formação profissional especificamente destinada à coordenação de cursos, dentro ou fora do Centro Paula Souza: 
Gráfico 3 - Atividades de formação [com temática específica sobre a coordenação de cursos] desenvolvidas pelos coordenadores nos últimos 12 meses, em percentuais

cursos/seminários exclusivamente sobre conteúdos e métodos de coordenação de cursos

cursos/seminários/oficinas presenciais relacionados à Educação

cursos/seminários/oficinas online/semipresenciais relacionados à Educação

congressos ou conferências de educação em que são apresentadas pesquisas ou discutem temas educacionais] leitura de textos/bibliografia especializada e direcionada à coordenação e gestão

outras atividades no período

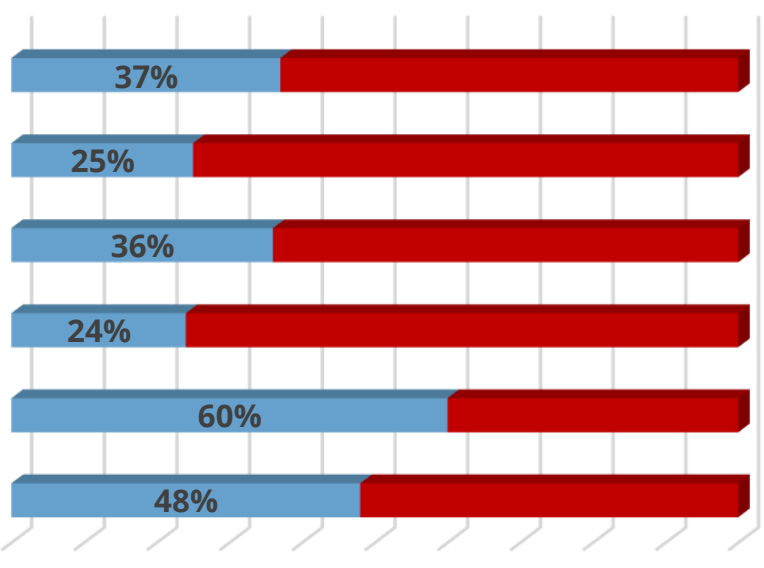

$\begin{array}{lllllllllll}0 \% & 10 \% & 20 \% & 30 \% & 40 \% & 50 \% & 60 \% & 70 \% & 80 \% & 90 \% & 100 \%\end{array}$

- Sim $\mathbf{n}$ ão

Fonte: (AUTORES, 2021).

Ao comparar estes dados com os resultados apresentados no Gráfico 2, observa-se que a formação continuada com temática específica se apresentou mais restrita, mas não irrelevante. Tomando-se, por exemplo, que 37\% dos respondentes frequentaram cursos sobre coordenação de cursos e 60\% acessaram bibliografia especializada sobre a temática, apresentam-se indicadores que confirmam o interesse destes profissionais em manterem-se atualizados e também desempenharem o previsto em suas atribuições funcionais, como apontado no item VII da Deliberação CEETEPS no 19/2015 (CEETEPS, 2015).

No campo da formação continuada em serviço, $46 \%$ dos consultados consideraram as capacitações ${ }^{6}$ oferecidas pelo Centro Paula Souza aos coordenadores de curso das Etecs suficientes quanto à sua periodicidade, enquanto 35\% consideraram insuficientes. Para um incremento deste atendimento, entendemos que ações adicionais ainda poderiam ser promovidas, individualmente pelas unidades escolares, e institucionalmente pelos Núcleos Regionais Administrativos em parceria

\footnotetext{
${ }^{6}$ Não pretendemos aqui salientar diferenças conceituais entre "formação continuada em serviço", "capacitação" ou "treinamento", simplesmente adotando a terminologia comumente adotada pela Cetec para este tipo de atividade.
} 
com a Cetec Capacitações 7 , bem como outros departamentos e organismos internos do Centro Paula Souza.

Gráfico 4 - Considerações dos coordenadores de curso sobre a formação continuada em serviço voltada ao seu eixo temático, quanto à periodicidade de sua oferta no Centro Paula Souza [em percentuais]

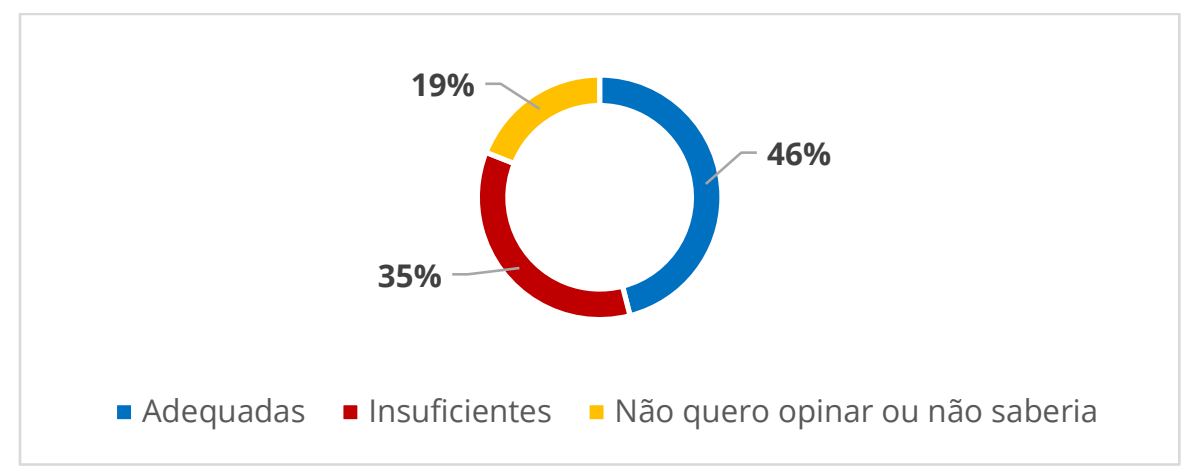

Fonte: (AUTORES, 2021).

Somado aos 19\% que não quiseram ou não souberam opinar sobre esta frequência das capacitações para coordenadores de cursos no Centro Paula Souza, existe um contingente de 54\% que, no mínimo, estaria enfrentando problemas para acessar ou reconhecer as informações sobre formação continuada na instituição. Trata-se aqui de uma oportunidade de melhoria para a comunicação institucional, pois $73,4 \%$ dos coordenadores afirmavam [na questão 15 do formulário] que acessavam regularmente informações sobre oportunidades de formação, o que nos leva a interpretar que a qualidade da informação seria relevante para a melhoria dos indicadores e o aproveitamento final destas ações.

Considerando uma reflexão estimulada entre os participantes da pesquisa, no gráfico a seguir estão demonstrados os percentuais relacionados às necessidades especificadas pelos coordenadores para estas possíveis atividades de formação, em uma escala de graduação que vai de 'grande' até 'nenhuma' necessidade, baseado nas atribuições funcionais previstas na Deliberação (CEETEPS, 2015) e na atuação reconhecida dos coordenadores de curso de Etecs:

\footnotetext{
7 Departamento diretamente ligado à Cetec, atende atualmente às Etecs e Fatecs para a promoção de formação continuada em serviço.
} 
Gráfico 5 - Em que medida os pesquisados consideram que necessitariam [no momento] de formação profissional para a coordenação de cursos sobre os seguintes aspectos, em percentuais

Aspectos legais envolvidos na educação básica e profissional (legislação educacional interna e externa

Conhecimento das propostas curriculares [planos de curso] e do projeto pedagógico da Etec

Promoção e atuação da gestão escolar participativa e compartilhada, por meio dos organismos disponiveis (Conselhos de classe e escolar, Grêmio Estudantil, Cooperativa escola, outros)

Atuação para a inclus̃ão dos alunos com deficiências ou quaisquer necessidades especiais de aprendizagem

Habilidades com as tecnologias da informação e da comunicação

Mediação de relações interpessoais e/ou de conflitos no ambiente escolar

Promoção da equidade e diversidade na escola

Desenvolvimento de atividades e colaborações com outros atores descentralizada, coordenador pedagógico, etc.)

Supervisão e coordenação junto aos professores, do planejamento execução dos trabalhos de conclusão de curso (TCC)

Orientação e acompanhamento das atividades de recuperação e de progressão parcial

Coordenação das atividades vinculadas ao estágio (obrigatório ou não) dos alunos ou dos projetos de voluntariado

Coleta e tratamento de dados para estudos e análises, visando a tomada de decisões na escola

Avaliação do desempenho dos Docentes e Auxiliares de Docentes

Gerenciamento da atuação dos Auxiliares de Docentes

Planejamento e avaliação de atividades extracurriculares de curta duração, palestras e visitas técnicas

Acompanhamento do cumprimento curricular: aulas previstas e dadas, reposições/substituições

Coordenação do planejamento e desenvolvimento do trabalho docente

Conhecimento e compreensão de práticas de coordenação/gestão de cursos no ensino médio e técnico

Conhecimento e compreensão sobre novas pesquisas e teorias sobre a Educação
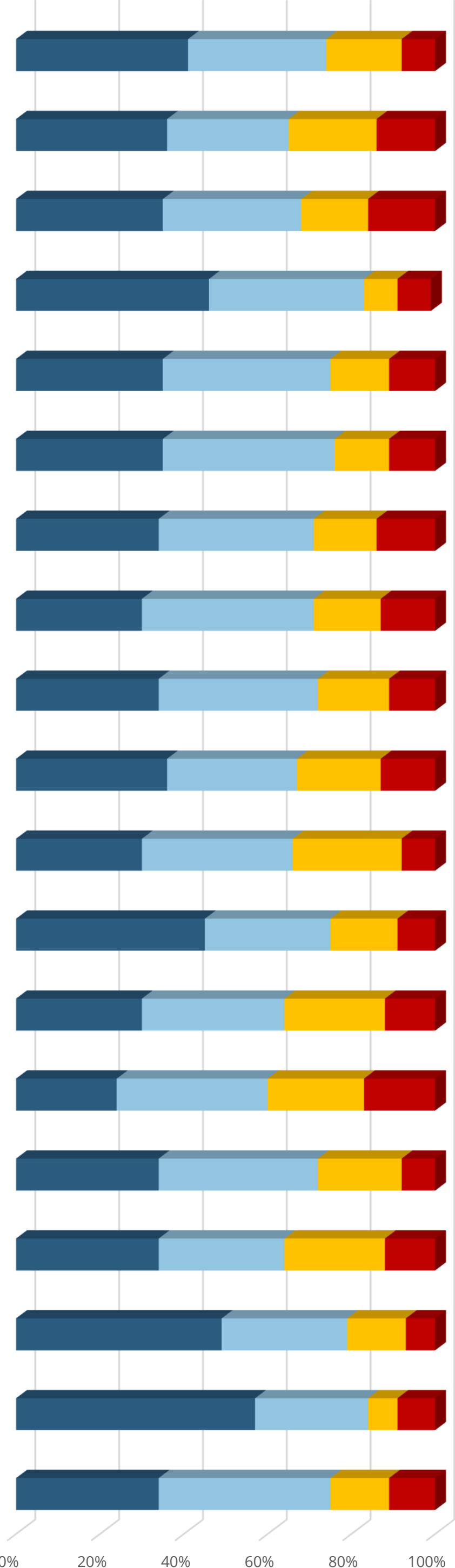

$0 \%$ 
Entre as demandas de formação prementes, destacam-se o conhecimento e práticas de gestão de cursos no ensino médio e técnico [57\% observaram grande necessidade], o planejamento e envolvimento dos docentes nas atividades escolares [49\%], a atuação para inclusão dos alunos com deficiências de qualquer ordem ou dificuldades de aprendizagem [46\%] e a coleta e tratamento de dados para estudos e análises no contexto escolar [45\%]. A demanda menos acionada foi aquela relacionada à gestão do trabalho dos auxiliares de docente $[40 \%$ viram pouca ou nenhuma necessidade], o que poderia ser explicado pela indisponibilidade destes profissionais à totalidade dos cursos nas Etecs ${ }^{8}$; seguida do acompanhamento das atividades escolares, aula dadas e reposições [36\% pouca/nenhuma], para a qual existe farta documentação e regulação emanada da Administração Central do Centro Paula Souza. A formação para a gestão participativa também foi pouco acionada [32\%], o que demonstra a intensa circulação deste discurso e dos recursos para seu exercício no âmbito das Etecs. A atuação para inclusão dos alunos com deficiências de qualquer ordem ou dificuldades de aprendizagem exige uma formação pedagógica sólida, quer na preocupação com a própria formação dos alunos, quer no trabalho de conscientização e sensibilização da comunidade escolar, o que se refletiu na demanda apontada.

Destacamos ainda no Gráfico 5 a soma dos percentuais de 'grande necessidade' e 'necessidade moderada' [74\%] quanto à importância da formação em 'aspectos legais envolvidos na educação básica e profissional [legislação educacional interna e externa]'. Trata-se de uma demanda formativa com aderência na literatura especializada:

As leis e regulamentos oficiais devem ser do conhecimento de todos. Tanto o funcionamento institucional nos seus aspectos organizacionais e pedagógicos, quanto a vida pessoal e profissional dos profissionais da escola, em boa parte, decorrentes de expedientes legislativos e administrativos. (LIBÂNEO, 2013, p. 171)

O domínio dos elementos comunicacionais e da gestão de dados, relacionado ao item da pesquisa 'coleta e tratamento de dados para estudos e análises, visando a tomada de decisões na escola', apresentou 45\% de 'grande necessidade' e 30\% de 'necessidade

\footnotetext{
${ }^{8}$ Um levantamento realizado em 2012 apontava que 42\% das escolas técnicas estaduais não possuía nenhum auxiliar de docente no seu quadro de funcionários (CONSTANTINO, 2013). Não há razão para entender que o cenário tenha se modificado positivamente, pois na última década ocorreu a expansão do número de Etecs e a redução substancial dos concursos públicos para o provimento de cargos de apoio educacional.
} 
moderada', apontando a preocupação dos coordenadores em empregar indicadores para tomada de decisões na unidade escolar, bem como nas questões estratégicas e de planejamento em médio e longo prazos. Associa-se estreitamente às necessidades reveladas em 'habilidades com as tecnologias da informação e da comunicação', que foram sinalizadas pelos coordenadores em um total de 75\% das manifestações, sendo 35\% em 'grande necessidade' e 40\% em 'necessidade moderada', reforçando a importância destes recursos para os alunos e professores/coordenadores.

A 'mediação de relações interpessoais e/ou de conflitos no ambiente escolar', também se coloca entre 76\% dos coordenadores consultados, sendo 35\% em 'grande necessidade' e 41\% de 'moderada necessidade' de formação. Possivelmente esteja ligada às situações experimentadas ao gerenciarem conflitos no ambiente escolar, que vão desde problemas de agendamentos do mesmo dia/horário de equipamentos, salas e laboratórios pelos professores, conflitos de interesse em relação à atribuição de aulas, pontos de vista político-partidários, desacordos em relação aos resultados de avaliação discente, entre outros

Para além de indagar os coordenadores de curso sobre as necessidades e lacunas que identificavam em sua trajetória profissional, procurou-se mapear possíveis entraves para que estes sujeitos se dirigissem às atividades formativas, o que se demonstra no Gráfico 6.

Os principais entraves identificados [concordo totalmente/concordo] foram o custo financeiro para a participação nestas formações [49\%] e os locais de oferta fisicamente distantes de onde os coordenadores moram ou trabalham [47\%]. A instituição teria condições de sanar estas duas principais barreiras, pois os programas institucionais de formação de curta duração são gratuitos em sua totalidade [aos coordenadores e professores, por vezes, incluem-se os reembolsos de hospedagem e transporte] pela instituição e, no segundo caso, poderiam ser fortalecidos em polos regionais e nas atividades híbridas, entre ofertas presenciais e online. 94\% discordaram ou discordaram fortemente que não possuiriam requisitos mínimos para participar de uma formação destinada a coordenadores, o que demonstra a confiança dos profissionais em sua formação inicial e nas experiências de trabalho desempenhadas. Apesar de mencionarem que as formações em lugares distantes e o custo seriam entraves para sua participação, os coordenadores majoritariamente avaliaram que a 
instituição se preocupa com sua formação continuada em serviço, e a incentivaria de modo decisivo.

Gráfico 6 - Medida em que os coordenadores concordam ou discordam de que cada uma das afirmações representa uma barreira para sua participação em atividades de formação continuada para a coordenação de curso, em percentuais

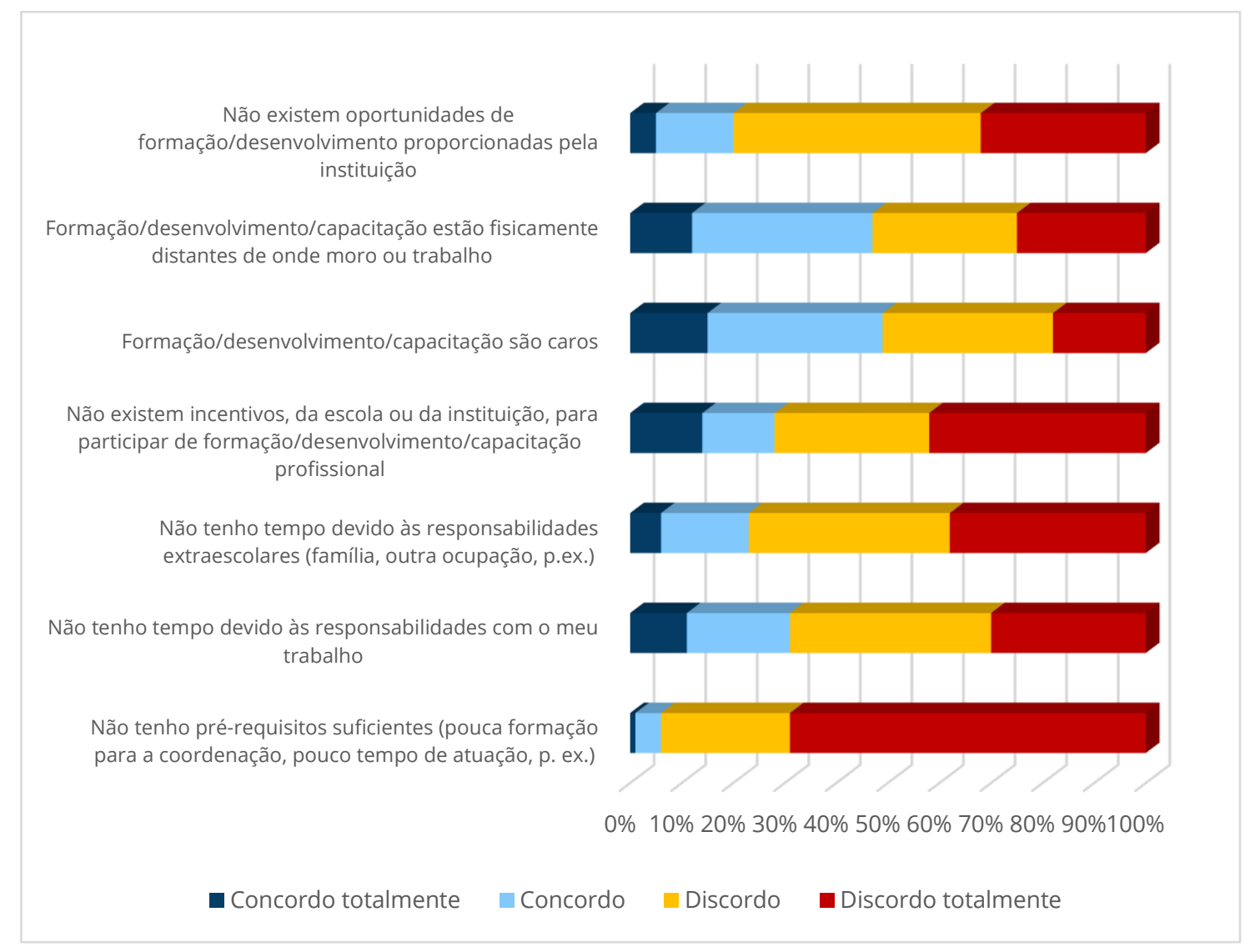

Fonte: (AUTORES, 2021).

Além destes elementos pontualmente destacados, os eixos fundantes da formação inicial e continuada do professor da educação profissional técnica, uma vez estendidos aos coordenadores de cursos, foram apontados nos Gráficos 5 e 6, afinal, foram sublinhados os saberes disciplinares específicos da sua área de atuação, os saberes da experiência profissional, os saberes pedagógicos e didáticos (REHEM, 2009) e os saberes da gestão escolar.

\section{Considerações finais}

O estudo pretendeu ampliar o entendimento das condições que a coordenação de cursos nas escolas técnicas estaduais de São Paulo, especialmente ligada ao Centro 
Paula Souza, apresentava no ano de 2020. A amostragem pode nos fornecer dados valiosos sobre o clima escolar e as possibilidades de inserção e desenvolvimento profissional destes atores nas atividades educacionais e gestionárias, que serão úteis para tomadas de decisão e formulação de políticas públicas em diferentes níveis, do microcosmo da unidade escolar à instituição em nível estadual. Oferece ainda a oportunidade de colocar em debate uma temática cuja literatura, no reduto da educação profissional, ainda se apresentou limitada no país.

Durante o trabalho buscou-se demonstrar o perfil dos coordenadores de cursos, baseado na legislação vigente e de como se constituiu historicamente este personagem nas Etecs, na busca das características que poderiam ser mapeadas sobre sua inserção profissional e formação. Nota-se que sua atual forma derivou de outras funções, durante a evolução e expansão das unidades escolares e do próprio sistema estadual em questão, conforme os registros iniciais da atividade de coordenação de área de 1988 (CEETPS, 1988) demonstraram, passando pelo seu momento mais incisivo na segunda década dos anos 2000. Posteriormente, a amplitude de suas competências foi se modificando e, de certo modo, se ajustando às demais presenças nas Etecs, como as dos coordenadores de classes descentralizadas, orientadores educacionais, diretores de serviços acadêmicos ou coordenadores pedagógicos.

O desenvolvimento de um quadro por área de atuação, mapeando as atribuições da Deliberação CEETEPS no 19, de 16-07-2015 (CEETEPS, 2015), permitiu uma análise mais ajustada das respostas fornecidas pelos coordenadores à pesquisa, a partir da classificação das respostas, para identificar os principais desafios enfrentados pelos pesquisados e sua condição de formação atual, aproximando-se do que eles estavam vivendo em sua trajetória profissional, ou revelando seus anseios e perspectivas quanto à função. A este exame, fizemos aproximações com o uso da literatura e de práticas reconhecidas de gestão escolar de nossa própria lavra.

Como informado, este volume é parte de um projeto mais amplo, ligado ao programa de Mestrado Profissional em Gestão e Desenvolvimento da Educação Profissional e à Unidade de Pós-Graduação, Extensão e Pesquisa do CEETEPS. Ulteriormente, se poderia avançar sobre os aspectos específicos da atuação dos coordenadores de cursos, podendo-se também eleger outros núcleos regionais para a 
coleta e o desenvolvimento das análises, ou mesmo outras instituições públicas de educação profissional, estabelecendo interlocuções e possíveis comparações.

O que se espera também é uma contribuição para a gestão pública da educação, em que sejam estimuladas e propiciadas as estruturas — em quantidade e qualidade necessárias —, a fim de que os coordenadores tenham a possibilidade de articular adequadamente os cursos, encontrando-se com investimentos que atendam às necessidades conjunturais e estruturais das unidades escolares, para abarcar a expansão dos novos programas de educação profissional como o Novotec, em suas diversas modalidades. Trata-se de uma discussão que não foi alimentada neste documento, mas que precisará ser abordada mais adiante, pois, com a expansão do governo estadual em relação ao programa Novotec, urge a necessidade de se alinhar as novas atribuições e competências exigidas dos coordenadores de cursos.

Apresentaram-se, finalmente, outros desafios inadiáveis, como o do reconhecimento financeiro da atividade de coordenação, o de contornar tarefas que não estão relacionadas às suas atribuições, a carga horária considerada insuficiente para cumprir com suas obrigações, bem como a perene necessidade institucional de propiciar uma formação específica para coordenadores e seus coordenados.

\section{Referências}

AQUINO, J. G.; MUSSI, M. C. As vicissitudes da formação docente em serviço: a proposta reflexiva em debate. Educação e Pesquisa, São Paulo, v. 27, n. 2, p. 211-227, 2001.

ARAÚJO, A. M.; COVELLO, A. A. (Orgs.). Planejamento e gestão da educaşão profissional. v. 5. São Paulo: CEETEPS, 2000.

ASSEMBLEIA LEGISLATIVA DO ESTADO DE SÃO PAULO (ALESP). Lei nº 16.279, de 8 de julho de 2016. Aprova o Plano Estadual de Educação de São Paulo e dá outras providências. Diário Oficial do Estado de São Paulo, 09 jul. 2016, p. 126-127.

BARROS, D. F.; ARAGÃO, R. M. R. Coordenação de cursos superiores: novas competências e habilidades. São Bernardo do Campo: Universidade Metodista de São Paulo, 2006.

BOSCHIERO, E. F. Construção da identidade do coordenador de área a partir do ponto de vista dos professores. In: ARAÚJO, A. M.; COVELLO, A. A. (Orgs.). Planejamento e gestão da educação profissional. São Paulo: CEETEPS, 2000. p. 125-134. v. 5.

BRASIL. Lei $\mathrm{n}^{\circ}$ 13.005, de 25 de junho de 2014. Aprova o Plano Nacional de Educação - PNE e dá outras providências. Brasília, 2014. Disponível em: 
http://www.planalto.gov.br/ccivil_03/_ato2011-2014/2014/lei/113005.htm. Acesso em: 20 set. 2020.

BRASIL. Lei no 9.394, de 20 de dezembro de 1996. Estabelece as diretrizes e bases da educação nacional. 23 dez. 1996. Disponível em: http://www.planalto.gov.br/ccivil_03/Leis/L9394.htm. Acesso em: 20 out. 2020.

BRASIL. Ministério da Educação (MEC). Pesquisa revela aumento de escolaridade dos docentes. 2021a. Disponível em: https://www.gov.br/mec/pt-br/assuntos/noticias/pesquisa-revelaaumento-de-escolaridade-dos-docentes. Acesso em: 13 mar. 2021.

BRASIL. Ministério da Educação (MEC). Resolução CNE/CP nº1/2021, de 05 de janeiro de 2021. Define as Diretrizes Curriculares Nacionais Gerais para a Educação Profissional e Tecnológica. 2021b. Disponível em: https://www.in.gov.br/web/dou/-/resolucaocne/cp-n-1-de-5-de-janeiro-de-2021-297767578. Acesso em: 02 mar. 2021.

CECCONI, A. O papel do coordenador de área na construção do planejamento pedagógico participativo. In: ARAÚJO, A. M.; COVELLO, A. A. (Orgs.). Planejamento e gestão da educaşão profissional. São Paulo: CEETEPS, 2000. p. 13-22. v. 5.

CENTRO ESTADUAL DE EDUCAÇÃO TECNOLÓGICA PAULA SOUZA (CEETPS). Deliberação CEETEPS nº 06, de 14 de dezembro de 2012. Dispõe sobre a Coordenação de Curso nas Escolas Técnicas Estaduais do CEETEPS. Diário Oficial de São Paulo, 18 dez. 2012.

CENTRO ESTADUAL DE EDUCAÇÃO TECNOLÓGICA PAULA SOUZA (CEETPS). Deliberação CEETEPS no 03, de 18 de julho de 2013. Aprova o Regimento Comum das Escolas Técnicas Estaduais do Centro Estadual de Educação Tecnológica Paula Souza. Diário Oficial de São Paulo, 28 ago. 2013. Disponível em: http://www.portal.cps.sp.gov.br/etec/regimentocomum/regimento-comum-2013.pdf/. Acesso em: 18 jul. 2020.

CENTRO ESTADUAL DE EDUCAÇÃO TECNOLÓGICA PAULA SOUZA (CEETPS). Deliberação CEETEPS n ${ }^{\circ}$ 19, de 16 de julho de 2015. Dispõe sobre a Coordenação de Curso nas Escolas Técnicas Estaduais do CEETEPS. Diário Oficial de São Paulo, 18 jul. 2015. Disponível em: http://www.cpscetec.com.br/cpscetec/doc_apoio_hae/2019/legislacao_vigente.zip. Acesso em: 20 out. 2020 .

CENTRO ESTADUAL DE EDUCAÇÃO TECNOLÓGICA PAULA SOUZA (CEETPS). Deliberação CEETPS nº 09, de 07 de dezembro de 1988. Institui atribuições, condições e formas de provimento das funções de Coordenador de Área das ETEs, do Centro Estadual de Educação Tecnológica "Paula Souza". Diário Oficial do Estado de São Paulo, 22 dez. 1988, p. 34.

CENTRO ESTADUAL DE EDUCAÇÃO TECNOLÓGICA PAULA SOUZA (CEETPS). Perfil e bistórico do Centro Paula Souza. [Website]. 2020a. Disponível em: http://www.cps.sp.gov.br/quem-somos/perfil-historico/. Acesso em: 20 out. 2020.

CENTRO ESTADUAL DE EDUCAÇÃO TECNOLÓGICA PAULA SOUZA (CEETPS). Unidade do Ensino Médio e Técnico do Centro Paula Souza (CETEC). Banco de dados da Unidade do Ensino Médio e Técnico do Centro Paula Souza [CETEC]. [Website]. 2020b. Disponível em: http://www.cpscetec.com.br/bdcetec. Acesso em: 22 abr. 2020.

CENTRO ESTADUAL DE EDUCAÇÃO TECNOLÓGICA PAULA SOUZA (CEETPS). Unidade do Ensino Médio e Técnico do Centro Paula Souza (CETEC). 
Instrução Cetec no 02, de 28 de junho de 2018. O Coordenador de Ensino Médio e Técnico, com base no artigo 11 da Deliberação CEETEPS no 019 de 16, publicada em 20 de julho de 2015, considerando a necessidade de orientar as Unidades de Ensino quanto à escolha e designação do Coordenador de Curso, expede a presente Instrução. 2018. Disponível em: http://www.cpscetec.com.br/cpscetec/doc_apoio_hae/2019/legislacao_vigente.zip.

Acesso em: 12 jan. 2021.

CONSTANTINO, P. R. P. O auxiliar de docente no contexto da educação profissional: uma reflexão no âmbito das escolas técnicas do Centro Paula Souza. In: SANT’ANNA, G. J. (Org.). Tarrafa pedagógica: o que experienciam nossos educadores. São Paulo: Editora Sucesso, 2013. p. 171-188.

CONSTANTINO, P. R. P. Quadro de atribuições da equipe pedagógica das Etecs. Assis: GSE/GEPED Marília, 2017. (Não publicado. Circulação restrita).

CONSTANTINO, P. R. P; AZEVEDO, M. M.; MENINO, S. E. Orientação educacional nas escolas técnicas estaduais de São Paulo: uma investigação sobre a inserção e atuação profissional. p. 01-25, 2021. No prelo.

CONSTANTINO, P. R. P; POLETINE, M. R. O. Coordenadores de curso no ensino técnico: relato de pesquisa-ação voltada à gestão da educação profissional. RLAEE - Revista Ibero-Americana de Estudos em Educação, Araraquara, v. 13, n. 1, p. 44-58, jan./mar. 2018.

ESTEVES, M.; RODRIGUES, A. A análise de necessidades na formação de professores. Porto: Porto Editora, 1993.

GATTI, B.A. Análise das políticas públicas para formação continuada no Brasil na última década. Revista Brasileira de Educação, Rio de Janeiro, v. 13, n. 37, p. 57-70, abr. 2008. Disponível em: http://www.scielo.br/scielo.php?script=sci_arttext\&pid=S1413$24782008000100006 \& \operatorname{lng}=$ en\&nrm=iso. Acesso em: 12 fev. 2021.

GIL, A. C. Métodos e técnicas de pesquisa social. 6. ed. São Paulo: Editora Atlas, 2008.

GOMES, H. M.; MARINS, H. O. A ação docente na educaşão profissional. São Paulo: Editora Senac São Paulo, 2003.

GUTSCHOW, M. P. A coordenação de cursos técnicos de Enfermagem: das práticas a proposta de formação. 2008. 77f. Dissertação (Mestrado em Desenvolvimento do Ensino Superior em Saúde). Universidade Federal de São Paulo, São Paulo, 2008.

LIBÂNEO, J. C. Organização e gestão da escola: teoria e prática. São Paulo: Heccus Editora, 2013.

LIMA, S. E. Educação profissional e tecnológica pública no Estado de São Paulo: um estudo a partir da expansão do Centro Paula Souza. 2020. 235 p. Dissertação (Mestrado Profissional em Gestão e Desenvolvimento da Educação Profissional) - Centro Estadual de Educação Tecnológica Paula Souza, São Paulo, 2020.

LÜCK, H. Dimensões de gestão escolar e suas competências. Curitiba: Editora Positivo, 2009.

LÜCK, H. Perspectivas da gestão escolar e implicações quanto à formação de seus gestores. Revista Em Aberto, Brasília, n. 72, p. 11-34, jun. 2000. Disponível em http://www.rbep.inep.gov.br/index.php/emaberto/article/view/1087/989. Acesso em: 09 set. 2020 . 
MARQUESIN, D. F. B.; PENTEADO, A. F.; BAPTISTA, D. C. O coordenador de curso da instituição de ensino superior: atribuições e expectativas. Revista de Educação, São Paulo, v. 11, n. 12, p. 7-21, 2008. Disponível em: https://revista.pgsskroton.com/index.php/educ/article/view/1917. Acesso em: 13 mar. 2021.

NÓVOA, A. Professores: imagens do futuro presente. Lisboa: Educa, 2009.

ORGANISATION FOR ECONOMIC CO-OPERATION AND DEVELOPMENT (OECD). TALIS 2018 Results (Volume I): teachers and school leaders as lifelong learners, TALIS. Paris: OECD Publishing, 2019.

REHEM, C. M. Perfil e formação do professor da educação profissional técnica. São Paulo: Editora Senac São Paulo, 2009.

SEABRA, A. L. C.; PAIVA, K. C. M.; LUZ, T. R. Competências gerenciais de coordenadoras de cursos de graduação em enfermagem. Revista Brasileira de Enfermagem, Brasília, v. 68, n. 5, p. $890-898$, out. 2015.

SILVA, H. C. S; CONSTANTINO, P. R. P. Processo de qualificação para coordenação pedagógica em escolas técnicas estaduais de São Paulo: um estudo exploratório. In: CONGRESSO BRASILEIRO DE EDUCAÇÃO, 7., Unesp, Bauru, 2019. Anais... Bauru: Faculdade de Ciências, 2019.

SOUZA, L C. Estrutura lógica de organização da pesquisa científica: texto básico para auxiliar pesquisadores. Belo Horizonte: EdUEMG, 2020.

RECEBIDO: 04/05/2021

APROVADO: $14 / 10 / 2021$

RECEIVED: 05/04/2021

APPROVED: $10 / 14 / 2021$

RECIBIDO: 04/05/2021

APROBADO: $14 / 10 / 2021$ 